\title{
Inpatient Glucose Control: A Glycemic Survey of 126 U.S. Hospitals
}

Curtiss B. Cook, MD, FACP ${ }^{1}$ Gail L. Kongable, RN, MSN, FNP² Daniel Jason Potter, $\mathrm{MA}^{2}$ Victor J. Abad, $\mathrm{mA}^{2}$

Dora E. Leija, $\mathrm{mA}^{2}$

Marcy Anderson, $\mathrm{ms}^{3}$

\author{
${ }^{1}$ Mayo Clinic College of Medicine, Scottsdale, Arizona. \\ ${ }^{2}$ The Epsilon Group Virginia, LLC, Charlottesville, Virginia. \\ ${ }^{3}$ Medical Automation Systems, Charlottesville, Virginia.
}

\begin{abstract}
This project was supported entirely by The Epsilon Group, Virginia, LLC. No additional funding was provided by Roche Diagnostics or Medical Automation Systems. Gail Kongable, Vic Abad, Daniel Potter, and Dora Leija are employed by The Epsilon Group, Virginia, while Marcy Anderson is employed by Medical Automation Systems. An agreement between Dr. Cook and The Epsilon Group was not in process at the time the work was conducted. After the first manuscript submission, a contractual arrangement was put in place between Mayo Clinic Arizona and The Epsilon Group. The work done during the manuscript revision process reflects effort done under this contractual arrangement.
\end{abstract}

BACKGROUND: Despite increased awareness of the value of treating inpatient hyperglycemia, little is known about glucose control in U.S. hospitals.

METHODS: The Remote Automated Laboratory System-Plus (RALS®-Plus Medical Automation Systems, Charlottesville, VA) was used to extract inpatient point-of-care bedside glucose (POC-BG) tests from 126 hospitals for the period January to December 2007. Patient-day-weighted mean POC-BG and hypoglycemia/hyperglycemia rates were calculated for intensive care unit (ICU) and non-ICU areas. The relationship of POC-BG levels with hospital characteristics was determined.

RESULTS: A total of 12,559,305 POC-BG measurements were analyzed: 2,935,167 from the ICU and 9,624,138 from the nonICU. Patient-day-weighted mean POC-BG was $165 \mathrm{mg} / \mathrm{dL}$ for ICU and $166 \mathrm{mg} / \mathrm{dL}$ for non-ICU. Hospital hyperglycemia ( $>180 \mathrm{mg} / \mathrm{dL}$ ) prevalence was $46.0 \%$ for ICU and $31.7 \%$ for non-ICU. Hospital hypoglycemia $(<70 \mathrm{mg} / \mathrm{dL}) \mathrm{prevalence} \mathrm{was}$ low at $10.1 \%$ for ICU and 3.5\% for non-ICU. For ICU and non-ICU there was a significant relationship between number of beds and patient-day-weighted mean POC-BG levels, with larger hospitals ( $\geq 400$ beds) having lower patient-day weighted mean POC-BG per patient day than smaller hospitals $(<200$ beds, $P<0.001)$. Rural hospitals had higher POC-BG levels compared to urban and academic hospitals $(P<0.05)$, and hospitals in the West had the lowest values.

CONCLUSIONS: POC-BG data captured through automated data management software can support hospital efforts to monitor the status of inpatient glycemic control. From these data, hospital hyperglycemia is common, hypoglycemia prevalence is low, and POC-BG levels vary by hospital characteristics. Increased hospital participation in data collection and reporting may facilitate the creation of a national benchmarking process for the development of best practices and improved inpatient hyperglycemia management. Journal of Hospital Medicine 2009;4:E7-E17. ( $) 2009$ Society of Hospital Medicine.

KEYWORDS: glucose, hospital, ICU, non-ICU.

The past decade has seen an increase in the number of hospital discharges associated with a diabetes diagnosis. ${ }^{1,2}$ Diabetes is the fourth leading comorbid condition associated with any hospital discharge in the United States. ${ }^{3}$ Nearly one-third of diabetes patients require 2 or more hospitalizations in any given year, ${ }^{4}$ and inpatient stays account for the largest proportion of direct medical expenses incurred by persons with the disease. ${ }^{5}$

The hospital component of diabetes care has been receiving considerable attention. The advantage of effective inpatient diabetes management-with particular attention to improving glycemic control-is evident for a number of clinical situations (eg, acute myocardial infarction, critically ill patients) ${ }^{6-8}$ National and regional organizations, ${ }^{9-12}$ and professional societies ${ }^{6-8,12}$ have developed guidelines about management of inpatient hyperglycemia.

Despite increased awareness of the value of treating inpatient hyperglycemia, little is known about glucose control in U.S. hospitals. As hospitals begin to develop programs to improve inpatient glucose management, some method of standardized benchmarking should be put in place. Using information systems solutions to obtain pointof-care bedside glucose (POC-BG) data, we previously reported on inpatient glucose control from a smaller number of U.S. hospitals. ${ }^{13,14}$ We now provide data on a larger, more representative number of U.S. hospitals that gives a broader national view of the current status of inpatient glycemic control.

\section{Patients and Methods}

Data Collection

The hospitals in this study employed standard bedside glucose meters (ACCU-CHEK ${ }^{\circledR}$ Inform, Roche Diagnostics, Indianapolis, IN), downloaded to the Remote Automated Laboratory System-Plus (RALS ${ }^{\circledR}$-Plus; Medical Automation Systems, Charlottesville, VA), a well-established POC test 
information management system. ${ }^{13-15}$ Participating hospitals do not provide patient specific data (eg, age, sex, race, diagnosis codes), but individual patients can be selected based on a unique anonymous identifier. Data also includes date and time of the POC-BG test, download location (nursing unit), and the test result. Patient-level POC-BG data was extracted by linking the POC-BG data to the unique patient identifier. Adult inpatient data from January to December 2007 were collected. Out-of-range values of "LO" (<10 mg/ $\mathrm{dL}$ ) and "HI" (>600 mg/dL) were discarded. The number of $\mathrm{HI} / \mathrm{LO}$ values totaled less than $0.4 \%$ of the measurements. Repeat measures, largely performed to verify hypoglycemia were found to be present for $<3 \%$ of the measures and were retained in this analyses.

\section{Hospital Selection}

Participating hospitals were included through self-selection based on interest and a willingness to complete a business agreement prior to a data collection deadline. All of the more than 1300 hospitals with RALS-Plus capability were invited to participate in the RALS-Annual Report, ${ }^{16}$ an ongoing benchmarking project of inpatient glucose control in U.S. hospitals; 126 hospitals agreed to participate. Hospitals provided written permission to remotely access their RALS-Plus glucose data and combine it with other participating hospitals into an aggregate database. Confidentiality was guaranteed for the identity of participating hospitals and their data.

Characteristics of participating hospitals, including number of beds, type (academic, urban community, rural community), and region, were obtained via completion of a questionnaire. This information was verified by accessing the hospital website or consulting the 2008 Hospital Blue Book (Official National Edition; Billian Publishing, Inc., Atlanta, GA). For academic status, we used membership in the Association of American Medical Colleges' Council of Teaching Hospitals, which is limited to organizations having a documented affiliation agreement with a medical school. Our definition of hospital types for the 126 study hospitals was based on first selecting the academic hospitals as a separate subgroup. The remaining hospitals were then classified as urban community or rural community.

\section{Statistical Analysis}

Glucose data were normalized to patient-day, and expressed according to the number of patient-days during which measurements were obtained. Patient-day analyses were conducted by first constructing a patient-day POC-BG mean. An average POC-BG level was computed for each patient-day by summing together the measurement occasions for a given patient-day and dividing by the number of measurements that occurred on that day. These patient-day averages were then aggregated to the hospital level, and averaged to compute the patient-day-weighted mean POC-

\begin{tabular}{|c|c|c|c|}
\hline & $\begin{array}{l}\text { Study } \\
\text { Hospitals }\end{array}$ & $\begin{array}{l}\text { RALS-Plus } \\
\text { Hospitals }\end{array}$ & $\begin{array}{l}\text { U.S. } \\
\text { Hospitals }\end{array}$ \\
\hline Total & 126 & 1225 & $4936^{\dagger}$ \\
\hline \multicolumn{4}{|c|}{ Number of beds, $n(\%)$} \\
\hline$<200$ & $48(38.1)$ & $510(41.6)$ & $3532(71.6)$ \\
\hline 200-299 & $25(19.8)$ & $284(23.2)$ & $619(12.5)$ \\
\hline 300-399 & $17(13.5)$ & $193(15.8)$ & $368(7.5)$ \\
\hline$\geq 400$ & $36(28.6)$ & $238(19.4)$ & $417(8.4)$ \\
\hline \multicolumn{4}{|c|}{ Hospital type, n (\%) } \\
\hline Academic & $11(8.7)$ & $74(6.0)$ & $413(8.4)$ \\
\hline Urban & $69(54.8)$ & $835(68.2)$ & $2514(50.9)$ \\
\hline Rural & $46(36.5)$ & $316(25.8)$ & $2009(40.7)$ \\
\hline \multicolumn{4}{|l|}{ Region, n (\%) } \\
\hline Northeast & $20(15.9)$ & $206(16.8)$ & $680(13.8)$ \\
\hline Midwest & $37(29.4)$ & $520(42.4)$ & $1422(28.8)$ \\
\hline South & $41(32.5)$ & $259(21.1)$ & $1919(38.9)$ \\
\hline West & $28(22.2)$ & $239(19.5)$ & $915(18.5)$ \\
\hline
\end{tabular}

*Based on AHA Hospital Statistics, published by Health Forum LLC, Chicago, IL, 2007. All U.S. community hospitals, defined as nonfederal, short-term general and specialty hospitals whose facilities and services are available to the public. The AHA Hospital Statistics categorizes hospitals into urban and rural, but does not report academic status of hospitals. Study sample was found to be representative of the larger sample of hospitals that use RALS-Plus with regard to bed number, hospital type, and region $(P=\mathrm{NS})$, but not representative of hospitals nationally in these categories $(P<0.05)$. Abbreviations: AHA, American Hospital Association; NS, not significant.

BG level for each hospital, using the patient-day as the unit of analysis.

Because of variations in the definition of maximal recommended inpatient glucose levels, ${ }^{8,9}$ we calculated proportion of patient-days with a patient-day-weighted mean POC-BG value above the cut points of $>180,>200,>250,>300$, $>350$, and $>400 \mathrm{mg} / \mathrm{dL}^{14,17}$ Published studies on hypoglycemia also use various biochemical definitions of low glucose ${ }^{18-24}$ therefore, we determined percentages of patient days with at least 1 POC-BG value below the different cut points $(<70,<60,<50$, and $<40 \mathrm{mg} / \mathrm{dL})$ as previously described. ${ }^{14,17}$

Finally, we evaluated the relationship between hospital patient-day-weighted mean POC-BG values (normalized to patient day as above) and specific hospital characteristics: number of hospital beds, hospital type (academic, urban community, rural community), and U.S. geographic region. Hospital groups were compared for continuous variables using Mann-Whitney tests and categorical variables (hospital characteristics) by chi-square tests. All analyses were done using SPSS ${ }^{\circ} 15.0$ (SPSS, Chicago, IL). Statistics were calculated for intensive care unit (ICU) and non-ICU locations separately.

\section{Results}

\section{Characteristics of Participating Hospitals}

Of the 126 participating hospitals (Table 1), 38.1\% were $<200$ beds, $19.8 \%$ were 200 to 299 beds, $13.5 \%$ were 300 to 399 beds, and $28.6 \%$ were $\geq 400$ beds; $54.8 \%$ were urban community hospitals, $36.5 \%$ were rural community, $8.7 \%$ 

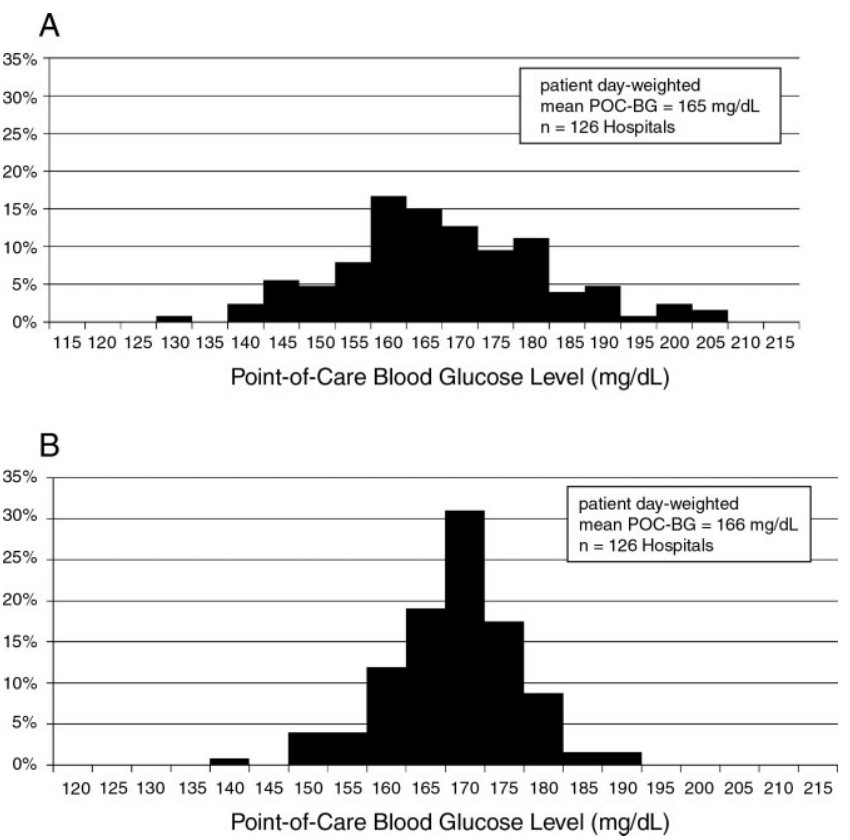

FIGURE 1. Point-of-care blood glucose (POC-BG) values for (A) ICU and (B) non-ICU settings. (A) Patient-day-weighted mean POC-BG $=165 \mathrm{mg} / \mathrm{dL}, \mathrm{n}=126$ hospitals. (B) Patientday-weighted mean POC-BG $=166 \mathrm{mg} / \mathrm{dL}, \mathrm{n}=126$ hospitals.

were academic, $32.5 \%$ were located in the South, $29.4 \%$ in the Midwest, $22.2 \%$ in the West, and $15.9 \%$ in the Northeast. Using chi-square comparison our study sample was found to be representative of the larger sample of hospitals that use RALS-Plus with regards to bed number, hospital type, and region $(P=$ not significant $[\mathrm{NS}])$, but not representative of hospitals nationally in these categories $(P<0.05)$. The most notable difference was seen in hospital size, where the sample hospitals were disproportionately larger; a trait shared by RALS hospitals more generally.

\section{Overall Glycemic Control}

A total of $12,559,305$ POC-BG measurements $(2,935,167$ from the ICU and 9,624,138 from the non-ICU) from $1,010,705$ patients with 3,973,460 patient days were analyzed from 126 hospitals. The mean number of measurements was 20 per ICU patient and 9.5 for non-ICU patients. The average number of measurements taken per patient-day was 5 for the ICU patient and 3 for the non-ICU patient.

Hospital hyperglycemia ( $>180 \mathrm{mg} / \mathrm{dL}$ ) was $46.0 \%$ for ICU and $31.7 \%$ for non-ICU. The patient-day-weighted mean POC-BG for ICU measurements was $165 \mathrm{mg} / \mathrm{dL}$ (median = $164 \mathrm{mg} / \mathrm{dL}, \mathrm{SD} \pm 14.5$ ) and $166 \mathrm{mg} / \mathrm{dL}$ (median $=167 \mathrm{mg} /$ $\mathrm{dL}, \mathrm{SD} \pm 8)$ for non-ICU. The distributions of patient-dayweighted mean POC-BG values for ICU and non-ICU settings are shown in Figure 1. The range of patient-dayweighted mean values was much wider for the ICU (126-203 $\mathrm{mg} / \mathrm{dL})$ than in the non-ICU (139-186 mg/dL).
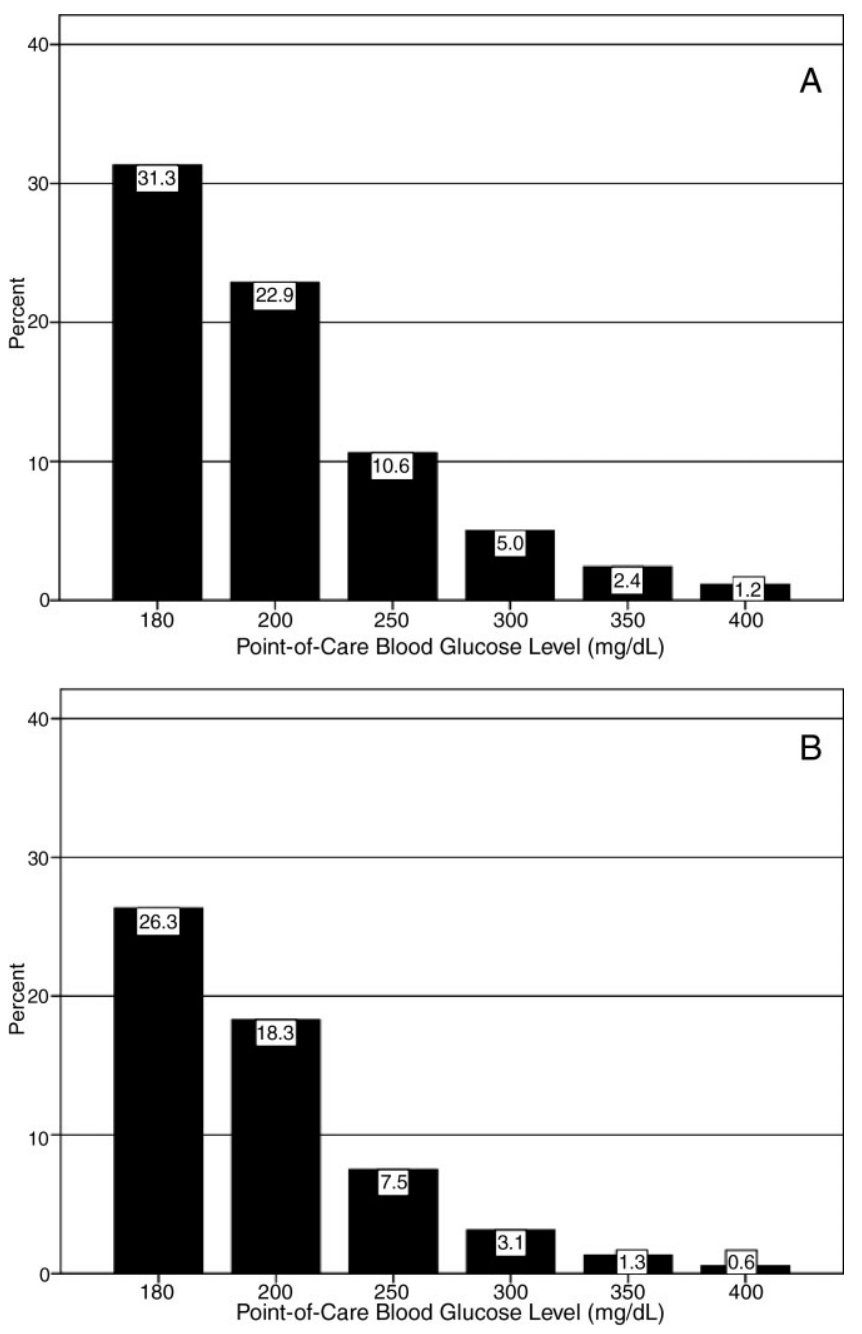

FIGURE 2. Percentage of patient-days where patient-dayweighted mean POC-BG value exceeded various cut points for the 126 U.S. hospitals during the January to December 2007 data collection period: (A) ICU and (B) non-ICU.

\section{Hyperglycemia Prevalence}

Of ICU patients, $60.6 \%$ had at least 1 POC-BG value $>180$ $\mathrm{mg} / \mathrm{dL}$, as did $46.4 \%$ of non-ICU patients. The proportion of patient-days with a patient-day-weighted mean POC-BG $>180 \mathrm{mg} / \mathrm{dL}$ was $26.3 \%$ in the ICU setting (Figure $2 \mathrm{~A}$ ) and $31.3 \%$ in the non-ICU (Figure 2B); the other cut points are also shown in Figure 2. The prevalence of patient-days where hyperglycemia was more severe $(>300 \mathrm{mg} / \mathrm{dL})$ was low but nonetheless still detected in both the ICU and nonICU settings, although these differences appear to be less pronounced than in the ICU.

\section{Hypoglycemia Rates}

There were $21.3 \%$ of patients who had at least 1 POC-BG value $<70 \mathrm{mg} / \mathrm{dL}$. Hospital hypoglycemia was low in both the ICU and non-ICU measurement data, although the 

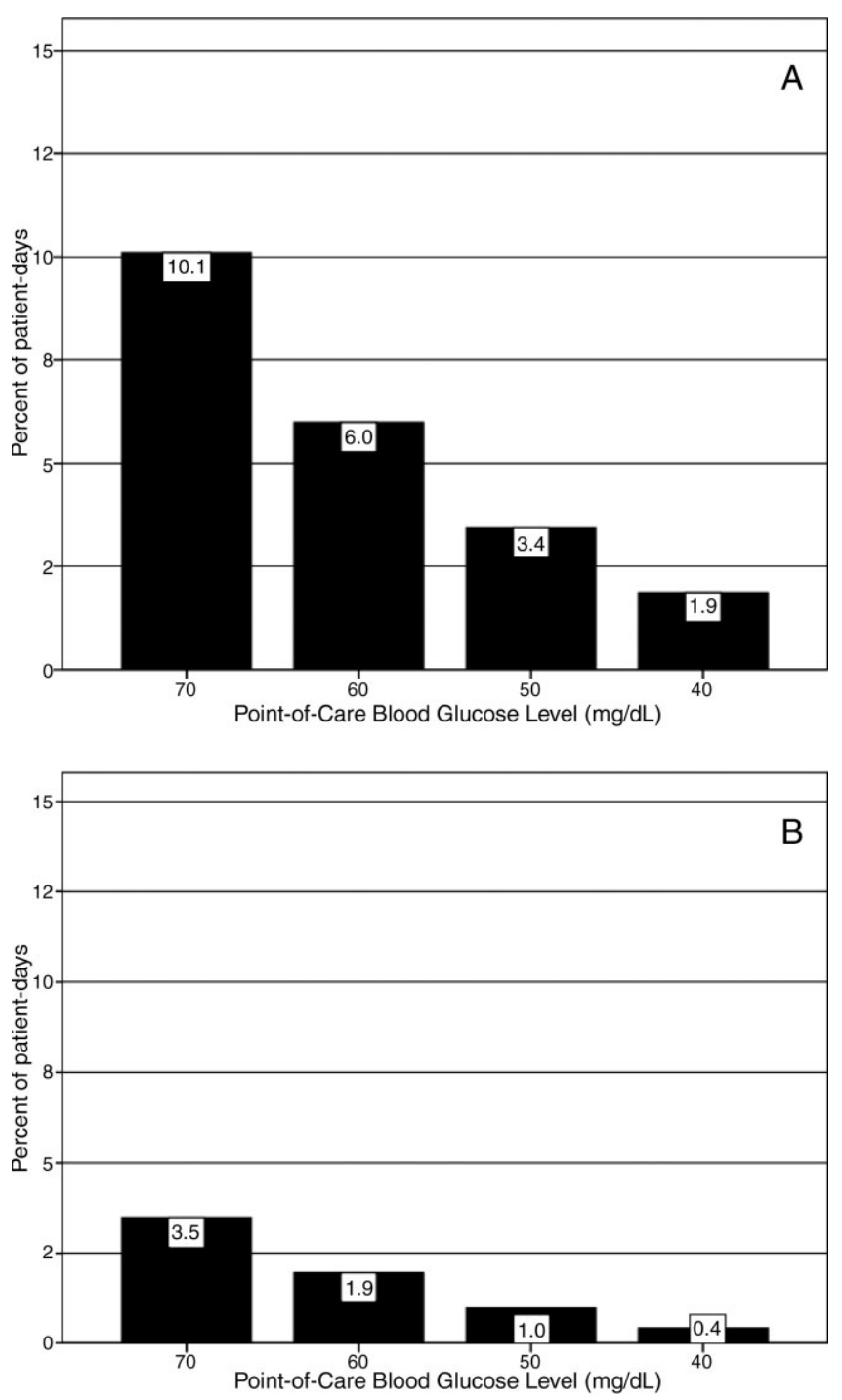

FIGURE 3. Percentage of patient-days where at least 1 hypoglycemia event ( $<70 \mathrm{mg} / \mathrm{dL})$ occurred in 126 U.S. hospitals during the January to December 2007 data collection period: (A) ICU and (B) non-ICU.

proportion of patient days with POC-BG $<70 \mathrm{mg} / \mathrm{dL}$ was higher in the ICU vs. the non-ICU setting (Figure 3A,B). Hypoglycemia $(<70 \mathrm{mg} / \mathrm{dL})$ was detected in $10.1 \%$ of patient-days $(3.2 \%$ of all measures) in the ICU setting (Figure $3 \mathrm{~A})$ and $3.5 \%$ of patient-days $(4.2 \%$ of all measures) in the non-ICU (Figure 3B). Moderate $(<60 \mathrm{mg} / \mathrm{dL})$ and more severe $(<50 \mathrm{mg} / \mathrm{dL}$ and $<40 \mathrm{mg} / \mathrm{dL})$ hypoglycemia were very uncommon in both the ICU and non-ICU.

\section{Relationship of Glucose Control with Hospital Characteristics}

There was a significant relationship between the total number of hospital beds and patient-day-weighted mean POCBG values in the ICU (Figure 4A). In the ICU, hospitals with $<200$ beds had significantly higher patient-day-weighted mean POC-BG levels than those with 200 to 299 beds $(P<$ $0.05), 300$ to 399 beds $(P<0.01)$, and $\geq 400$ beds $(P<$ 0.001 ). Rural hospitals (Figure $4 \mathrm{~B}$ ) also had higher patientday-weighted mean POC-BG values compared to urban community and academic hospitals (both $P<0.001$ ). Finally, ICUs in hospitals in the West (Figure 4C, bottom panel) had significantly lower values than those in the Midwest and South (both $P<0.01$ ).

Differences in patient-day-weighted mean POC-BG levels based on hospital characteristics were also observed for the non-ICU (Figure 5), although these differences appear to be less pronounced than in the ICU. Hospitals with $<200$ beds (Figure 5A) had significantly higher patient-day-weighted mean POC-BG values compared to hospitals with 300 to 399 beds $(P<0.05)$ and $\geq 400$ beds $(P<0.001)$. Rural hospitals (Figure 5B) had significantly higher values than academic $(P<0.05)$ and urban community $(P<0.001)$ hospitals, and hospitals in the West (Figure 5C) had significantly lower values than those in the South and Northeast (both $P<0.05$ ).

\section{Discussion}

Hospitalizations associated with diabetes pose a substantial burden on the U.S. health system. ${ }^{1-5}$ Recent consensus advocates good glucose control in the hospital to optimize outcomes for a number of clinical scenarios. ${ }^{6-8}$ Aside from a few institution-specific studies, ${ }^{25-27}$ the quality of diabetes treatment in U.S. hospitals is mostly unknown, but assessing the level of glycemic control will be a key metric that hospitals will need to track as they implement improvement programs targeting hospital hyperglycemia. Hospitals will need a way not just to track overall glucose levels, but also to monitor whether hypoglycemic events rise as they implement tight glycemic control initiatives. To our knowledge this is the first report on glycemic control from a large number of U.S. hospitals with diverse characteristics and from different geographic regions.

Debate continues as to what glucose targets for inpatients should be attained. ${ }^{28,29}$ The overall patient-dayweighted mean POC-BG was $170 \mathrm{mg} / \mathrm{dL}$ for the non-ICU, and only a moderately lower $162 \mathrm{mg} / \mathrm{dL}$ in the ICU, despite much lower thresholds for ICU measurements in current suggested guidelines. ${ }^{8,30}$ For the average hospital, over onethird of non-ICUs had patient-day-weighted mean POC-BG levels that were $>180 \mathrm{mg} / \mathrm{dL}$ and nearly one-quarter had values $>200 \mathrm{mg} / \mathrm{dL}$. Similarly, nearly $40 \%$ of ICUs had patient-day-weighted mean POC-BGs $>180 \mathrm{mg} / \mathrm{dL}$ and over $30 \%$ were $>200 \mathrm{mg} / \mathrm{dL}$, indicating room for improvement in hospital ICU glucose control, at least in the hospitals sampled here. The range of patient-day-weighted mean POC-BG levels for the ICU was broader than what was seen in the non-ICU data, with the ICU data containing lower weighted mean POC-BG values, and may indicate that hospitals are concentrating their efforts on adopting stricter glucose control measures in their ICUs. 
Whether examining data from a single institution, ${ }^{17}$ from a larger group of hospitals, ${ }^{14}$ or now from 126 hospitals, one consistent finding has been the low prevalence of hypoglycemia-particularly severe hypoglycemia (glucose $<50 \mathrm{mg}$ / $\mathrm{dL}$ or $<40 \mathrm{mg} / \mathrm{dL}$ ). Based on this larger sampling, however,
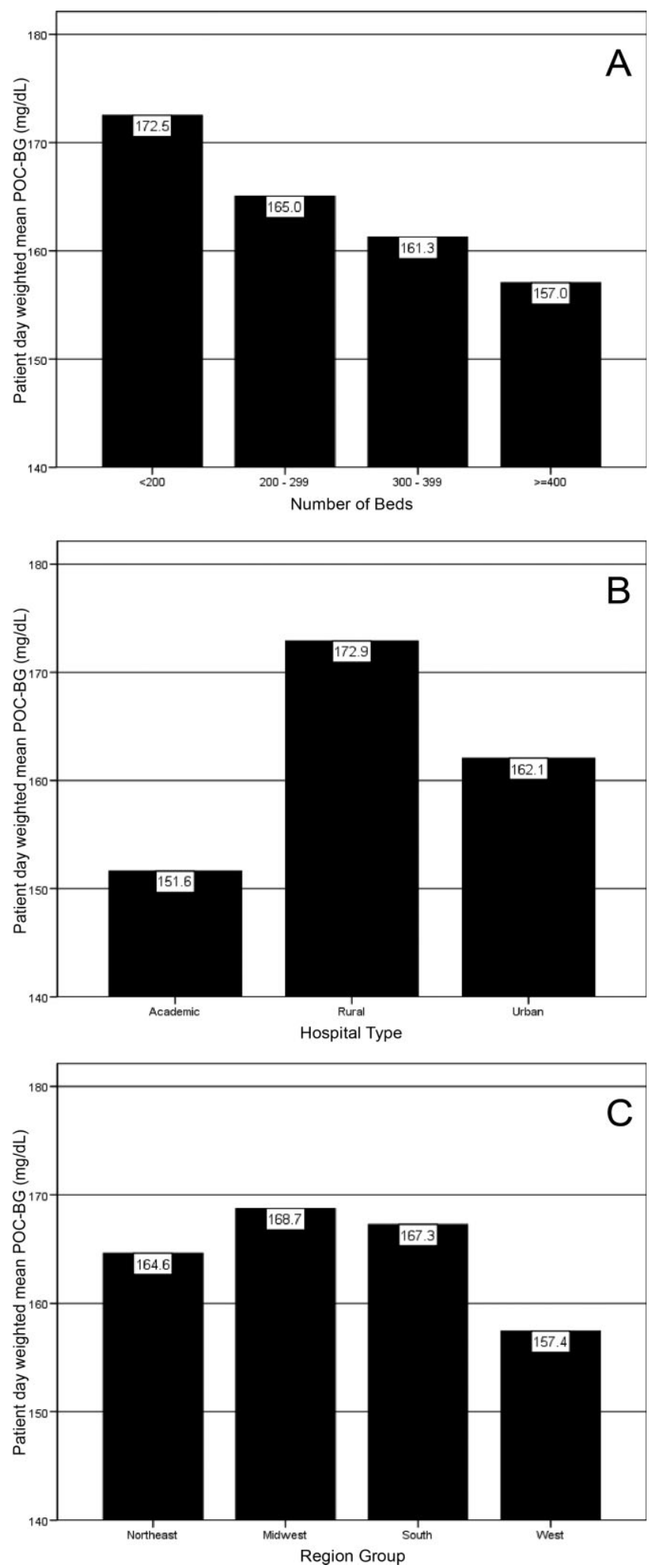

hypoglycemia in the ICU, while still uncommon with respect to hyperglycemia, is more than double that of the non-ICU. Fear of hypoglycemia is frequently mentioned as a barrier to attaining lower inpatient glucose levels. ${ }^{31}$ Although hypoglycemia frequency in the hospital is low, and even though recent data indicates that hypoglycemia is not perceived by practitioners as the number 1 barrier to successful inpatient diabetes management, ${ }^{32-34}$ the possible association of severe low glucose levels to inpatient mortality $^{18,19,21,22,24,35}$ makes hypoglycemia a key counterbalance metric that hospitals will need to track as they implement glycemic control programs. In the ICU, higher glycemic targets may be needed to allay practitioner fears, and insulin administration protocols that have the best track record for minimizing hypoglycemia should be identified and promulgated.

Recent data showing increased risk of hospital hypoglycemia with attempts to better control hyperglycemia may unjustifiably deter practitioners and hospitals from implementing programs to better control inpatient glucose levels. $^{24,36}$ Unlike the outpatient setting, where patients can take measures to prevent hypoglycemia, hospitalized patients surrender control of their diabetes management to staff. Inpatient tight glycemic control initiatives cannot be instituted unless they are coupled with efforts to understand and correct system-based problems that increase the risk of hypoglycemia. Recently published reports demonstrate that hypoglycemic events can be kept very low during treatment with an intensive insulin infusion protocol if expert rules are built into the algorithm that address hypoglycemia. ${ }^{37,38}$ Thus, rather than abandon efforts at improving inpatient hyperglycemia over concerns about hypoglycemia, hospitals will need to develop methods to change their hypoglycemia policies from ones that typically just guide treatment to ones that incorporate preventive strategies.

Our data suggest a relationship between POC-BG levels and hospital characteristics. Rural hospitals and hospitals with the least number of beds had higher POC-BG levels compared to urban, academic, or larger hospitals, especially in the ICU setting. The reasons underlying these findings cannot be determined from this analysis, but it is possible

FIGURE 4. Relationship of ICU patient-day-weighted mean POC-BG levels to hospital characteristics. (A) Hospitals with $<200$ beds had significantly higher patient-day-weighted mean POC-BG values compared to hospitals with 200 to 299 beds ( $P<0.05)$, 300 to 399 beds $(P<0.01)$, and $\geq 400$ beds $(P<0.001)$; hospitals with 200 to 299 beds also had greater patient-day-weighted mean POC-BG levels than hospitals with $\geq 400$ beds ( $P<0.05$ ). (B) Rural community hospitals had significantly higher values than urban community and academic hospitals (both $P<0.001$ ). (C) Hospitals in the West had significantly lower values than hospitals in the Midwest $(P<0.01)$ and South $(P<0.001)$. 
that smaller hospitals and those located in rural areas do not have access to the diabetes experts (eg, endocrinologists or diabetes educators) to assist them in developing tight glycemic control programs. We also detected differences in patient-day-weighted mean POC-BG data based on geo-
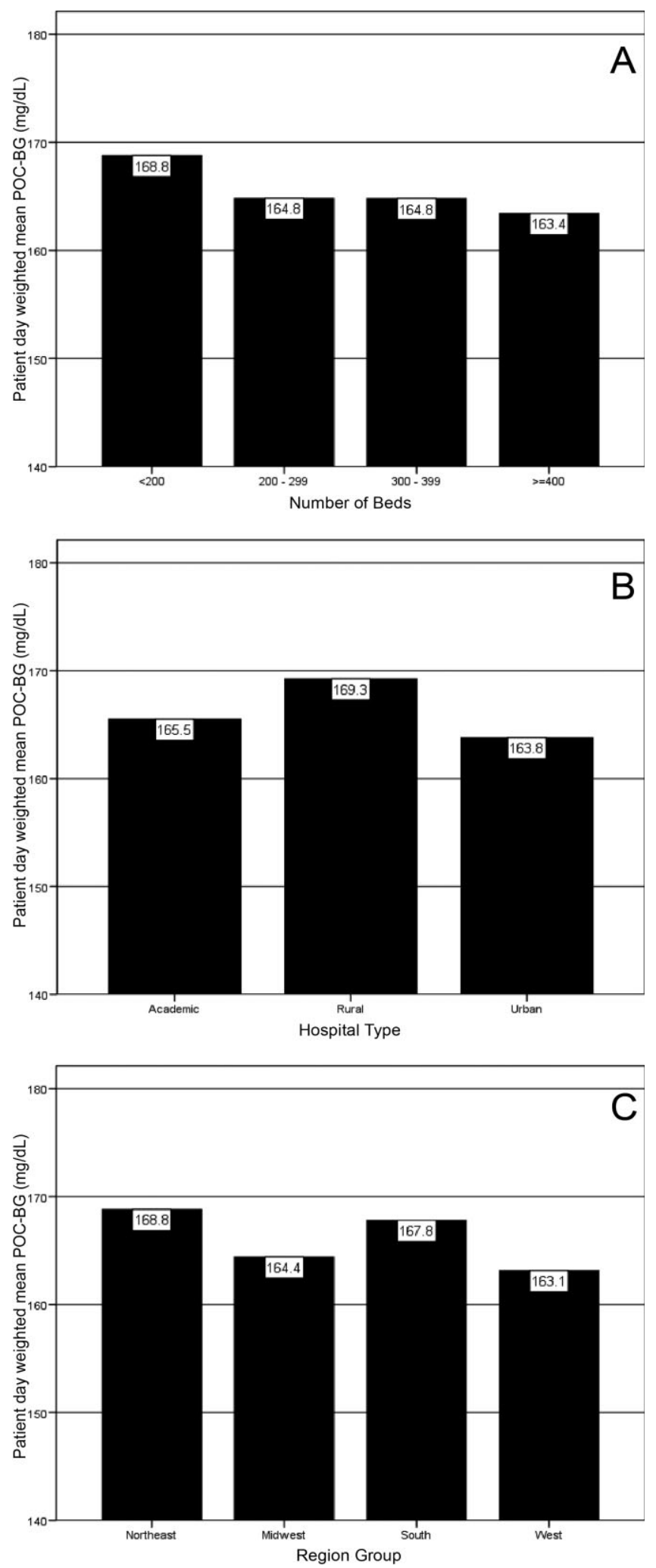

graphic region. Whether considering ICU or non-ICU data, hospitals located in the West had lower glucose values compared to other regions. As with the other hospital characteristics, the explanation underlying these observations cannot be determined. It is possible that hospitals in the West are earlier-adopters of tight glycemic control programs compared to other U.S. geographic regions. Further study is needed in a larger number of hospitals to confirm these findings.

These findings should be considered in light of the following limitations: unavailability to us of specific patientlevel information that would allow adjustment of data for such as variables as comorbidity; the fact that recommendations about glycemic targets in the hospital vary by organization, ${ }^{8-10,30}$ which may result in hospitals aiming for different targets in different populations; and the controversy that continues on the benefits of glycemic control in the ICU, which may be dissuading facilities from implementing glucose control programs. ${ }^{39,40}$ All that can be concluded from our analysis is that there is variation in the POC-BG data based on hospital characteristics. We cannot state that one type of hospital is performing glycemic control better than another, particularly as some hospital types are underrepresented in our sample, and we cannot control for patient-level data. Moreover, this statistical variation seen between different hospital types may not be of clinical importance in terms of being associated with different outcomes, or may simply be a result of different patterns of glucose monitoring in individual hospitals. However, the observed variation should prompt further investigation into the basis of differences (eg, some hospital types or regions may be further ahead in inpatient diabetes quality improvement initiatives than others).

There is no consensus about how best to summarize and report glycemic control in the hospital (so called "glucometrics"), ${ }^{41}$ and a variety of reporting measures have been suggested. ${ }^{20,42-45}$ We show data using one method: with the mean BG normalized to patient-day as the unit of analysis; however, we found similar results when we used the patient or the glucose reading as the unit of analysis. As organizations move to develop standards for summarizing inpatient glucose data, consideration must be given to which measure is best correlated with hospital outcomes. In addition, when developing standards, it will be important to determine

FIGURE 5. Relationship of non-ICU patient-day-weighted mean POC-BG levels to hospital characteristics. (A) Hospitals with $<200$ beds had significantly higher patientday-weighted-mean POC-BG values compared to hospitals with 300 to 399 beds $(P<0.05)$ and $\geq 400$ beds $(P<0.001)$. (B) Rural hospitals had significantly higher values than academic $(P<0.05)$ and urban community $(P<0.001)$ hospitals. (C) Hospitals in the West had significantly lower values than hospitals in the South and Northeast (both $P<$ 0.05).

2009 Society of Hospital Medicine DOI 10.1002/jhm.533

Published online in wiley InterScience (www.interscience.wiley.com). 
what type of data hospitals will find most clinically useful to track the impact of glucose control interventions. For instance, hospitals may wish to see data on the frequencies of glucose measurements that are above and below certain desired thresholds, which is one of the approaches that we have used in previous publications, ${ }^{14,17,26,46}$ and which is currently provided as feedback to hospitals participating in RALS reporting.

The other issue to address in development of standards in inpatient glycemic control reporting is what method of glucose measurement should be used. Correlation between whole-blood vs. POC-BG values can be imprecise in the intensive care setting. ${ }^{41,47}$ We have previously utilized bedside glucose measurements as our means of evaluating the status of inpatient glucose control, ${ }^{14,17,26}$ and bedside glucose measurements remain the mainstay of how practitioners judge the status of inpatient hyperglycemia and make therapeutic decisions about management. The hospitals participating in the process reviewed here all use the same system of bedside glucose monitoring and glucometer-laboratory electronic interface. Until alternative clinical methods are developed to frequently sample glucose levels in a convenient and minimally invasive way at the bedside, current POC-BG technology will continue to be the most utilized means of assessing hospital glucose management in the inpatient setting.

Electronic data warehouses such as RALS-Plus are convenient sources of information in which to store data on the quality of inpatient diabetes care. Unlike chart abstraction which requires extensive man-hours to extract data on a few patients, use of electronic data allows examination of large numbers of hospital cases. Queries of information systems could be automated, report cards potentially generated, and feedback given to providers and hospitals on the status of inpatient glycemic control.

Nonetheless, there are limitations to using electronic records as the sole method to assess inpatient diabetes care. Analysis of electronic records does not allow assessment of reasons underlying decision-making behavior of clinicians (eg, why they did or did not change hyperglycemic therapy). Moreover, our electronic data does not permit an assessment of who had preexisting diabetes, who was admitted with new onset diabetes, or who developed hyperglycemia as a result of the hospital stay.

In addition to the above, while our sample was representative of other RALs participating hospitals, it was not entirely representative of all U.S. hospitals. Hospitals contributing data to this report were chosen by self-selection rather than by random methods. Expanding hospital participation in this inpatient glucose assessment benchmarking process will be needed to determine if findings in this work can be generalized. Finally, our study was conducted using the hospital, rather than the patient, as the unit of analysis, as patient-level characteristics (age, sex, race/ethnicity) were not provided by participating hospitals.
Despite these limitations and issues noted above, to our knowledge this report is the most extensive review of the state of blood glucose control in hospitals across the United States. While other commercial laboratory data management systems may exist in hospitals, their data has not been reported to date. Additionally, our analysis provides a first glimpse of inpatient glycemic control of a large number of U.S. hospitals of varying characteristics and different national regions. Increased hospital participation in data collection may allow the creation of a national benchmarking process for the development of best practices and improved inpatient hyperglycemia management.

\section{Address for correspondence and reprint requests:}

Gail L. Kongable, RN, MSN, FNP, The Epsilon Group Virginia, LLC, 615 Woodbrook Drive, Suite B, Charlottesville, VA 22901; Telephone: 434-975-0097; Fax: 434-975-0477; E-mail: gkongable@epsilongroup.com Received 8 July 2008; revision received 23 February 2009; accepted 15 March 2009.

\section{References}

1. Centers for Disease Control and Prevention. Hospitalization for Diabetes as First-Listed Diagnosis. Available at: http://www.cdc.gov/diabetes/ statistics/dmfirst/index.htm. Accessed April 2009.

2. Centers for Disease Control and Prevention. Hospitalizations for Diabetes as Any-Listed Diagnosis. Available at: http://www.cdc.gov/diabetes/ statistics/dmany/index.htm. Accessed April 2009.

3. Elixhauser A, Yu K, Steiner C, Bierman AS. Hospitalization in the United States, 1997. Rockville, MD: Agency for Healthcare Research and Quality; 2000. HCUP Fact Book No. 1; AHRQ Publication No. 00-0031.

4. Jiang HJ, Stryer D, Friedman B, Andrews R. Multiple hospitalizations for patients with diabetes. Diabetes Care. 2003;26(5):1421-1426.

5. American Diabetes Association. Economic costs of diabetes in the US in 2007. Diabetes Care. 2008;31(3):596-615.

6. Clement S, SS B, Magee MF, et al. American Diabetes Association Diabetes in Hospitals Writing Committee: Management of diabetes and hyperglycemia in hospitals. Diabetes Care. 2004;27:553-591.

7. ACE Task Force on Inpatient Diabetes and Metabolic Control. American College of Endocrinology Position Statement on Inpatient Diabetes and Metabolic Control. Endocr Pract. 2004;10:77-82.

8. ACE/ADA Task Force on Inpatient Diabetes. American College of Endocrinology and American Diabetes Association consensus statement on inpatient diabetes and glycemic control. Endocr Pract. 2006;12(4):459-468.

9. Institute for Healthcare Improvement. Getting started kit: prevent surgical site infections. Available at: http://www.ihi.org/NR/rdonlyres/ 00EBAF1F-A29F-4822-ABCE-829573255AB8/0/SSIHowtoGuideFINAL.pdf. Accessed April 2009.

10. Institute for Healthcare Improvement. Implement Effective Glucose Control. Available at: http://www.ihi.org/IHI/Topics/CriticalCare/IntensiveCare/ Changes/ImplementEffectiveGlucoseControl.htm. Accessed April 2009.

11. Joint Commission on Accreditation of Healthcare Organizations. Inpatient Diabetes Certification Addendum. Available at: http://www.jointcommission.org/CertificationPrograms/Inpatient+Diabetes. Accessed April 2009.

12. Cook CB, Stockton L, Baird M, et al. Working to improve care of hospital hyperglycemia through statewide collaboration: the Georgia Hospital Association Diabetes Special Interest Group. Endocr Pract. 2007;13:45-50.

13. Moghissi Etie S, Kongable Gail L, Abad Victor J, Leija Dora E. Current state of inpatient diabetes burden and care, and goal of the conference. Endocr Pract. 2006;12:S1-S10.

14. Cook CB, Moghissi E, Renu J, Kongable GL, Abad VJ. Inpatient point-of-care bedside glucose testing: preliminary data on use of connectivity informatics to measure hospital glycemic control. Diabetes Technol Ther. 2007;9:493-500. 
15. Menke G. Medical automation systems and a brief history of point-ofcare informatics. Point Care. 2007;6:154-159.

16. Medical Automation Systems. RALS-Report. Available at: http://www. rals.com/RALS-Report.html. Accessed April 2009.

17. Cook CB, Castro JC, Schmidt RE, et al. Diabetes care in hospitalized noncritically ill patients: more evidence for clinical inertia and negative therapeutic momentum. J Hosp Med. 2007;2:203-211.

18. Fischer KF, Lees JA, Newman JH. Hypoglycemia in hospitalized patients. Causes and outcomes. N Engl J Med. 1986;315(20):1245-1250.

19. Stagnaro-Green A, Barton MK, Linekin PL, Corkery E, DeBeer K, Roman SH. Mortality in hospitalized patients with hypoglycemia and severe hyperglycemia. Mt Sinai J Med. 1995;62(6):422-426.

20. Queale WS, Seidler AJ, Brancati FL. Glycemic control and sliding scale insulin use in medical inpatients with diabetes mellitus. Arch Intern Med. 1997;157(5):545-552.

21. Rady MY, Johnson DJ, Patel BM, Larson JS, Helmers RA. Influence of individual characteristics on outcome of glycemic control in intensive care unit patients with or without diabetes mellitus. Mayo Clin Proc. 2005;80(12):1558-1567.

22. Vriesendorp TM, DeVries JH, van Santen S, et al. Evaluation of shortterm consequences of hypoglycemia in an intensive care unit. [see Comment]. Crit Care Med. 2006;34(11):2714-2718.

23. Vriesendorp Titia M, van Santen S, DeVries JH, et al. Predisposing factors for hypoglycemia in the intensive care unit. [see Comment]. Crit Care Med. 2006;34(1):96-101.

24. Krinsley JS. Severe hypoglycemia in critically ill patients: risk factors and outcomes. Crit Care Med. 2007;35(10):2262-2267.

25. Levetan CS, Passaro M, Jablonski K, Kass M, Ratner RE. Unrecognized diabetes among hospitalized patients. Diabetes Care. 1998;21(2):246-249.

26. Knecht LD, Gauthier SM, Castro JC, et al. Diabetes care in the non-ICU setting: is there clinical inertia in the hospital? J Hosp Med. 2006;1(3): 151-160.

27. Schnipper JL, Barsky EE, Shaykevich S, Fitzmaurice G, Pendergrass ML. Inpatient management of diabetes and hyperglycemia among general medicine patients at a large teaching hospital. J Hosp Med. 2006;1(3):145-150.

28. Inzucchi SE, Rosenstock J. Counterpoint: inpatient glucose management. A premature call to arms? Diabetes Care. 2005;28:976-979.

29. Bryer-Ash M, Garber AJ. Point: inpatient glucose management. The emperor finally has clothes. Diabetes Care. 2005;28(4):973-975.

30. Dellinger RP, Levy MM, Carlet JM, et al. Surviving Sepsis Campaign: international guidelines for management of severe sepsis and septic shock: 2008. Crit Care Med. 2008;36(1):296-327.

31. Braithwaite SS, Buie MM, Thompson CL, et al. Hospital hypoglycemia: not only treatment but also prevention. American College of Endocrinology (ACE) Inpatient Diabetes and Metabolic Control Consensus Conference. Endocr Pract. 2004;10(suppl 2):89-99.
32. Cook CB, McNaughton D, Braddy C, et al. Management of inpatient hyperglycemia: assessing perceptions and barriers to care among resident physicians. Endoc Pract. 2007;13:117-125.

33. Cook CB, Jameson KA, Hartsell ZC, et al. Beliefs about hospital diabetes and perceived barriers to glucose management among inpatient midlevel practitioners. Diabetes Educ. 2008;34(1):75-83.

34. Cheekati V, Osburne RC, Jameson KA, Cook CB. Perceptions of resident physicians about management of inpatient hyperglycemia in an urban hospital. J Hosp Med. 2009;4(1):E1-E8.

35. Mendoza A, Kim YN, Chernoff A. Hypoglycemia in hospitalized adult patients without diabetes. Endocr Pract. 2005;11(2):91-96.

36. Brunkhorst Frank M, Engel Christoph, Bloos Frank, et al. Intensive insulin therapy and pentastarch resuscitation in severe sepsis. $N$ Engl J Med. 2008;358(2):125-139.

37. Stockton L, Baird M, Cook CB, et al. Development and implementation of evidence-based, IV insulin guidelines: a statewide collaborative approach. Insulin. 2008;3:67-77.

38. Hermayer KL, Neal DE, Hushion TV, et al. Outcomes of a cardiothoracic intensive care web-based online intravenous insulin infusion calculator study at a Medical University Hospital. Diabetes Technol Ther. 2007;9(6):523-534.

39. Wiener RS, Wiener DC, Larson RJ. Benefits and risks of tight glucose control in critically ill adults. A meta-analysis. JAMA. 2008;300(8):933-944.

40. Finfer SF, Delaney A. Tight glycemic control in critically ill adults. JAMA. 2008;300(8):963-965.

41. Goldberg Philip A, Bozzo Janis E, Thomas Prem G, et al. "Glucometrics"-assessing the quality of inpatient glucose management. Diabetes Technol Ther. 2006;8(5):560-569.

42. Kosiborod M, Inzucchi SE, Krumholz HM, et al. Glucometrics in patients hospitalized with acute myocardial infarction: defining the optimal outcomes-based measure of risk. [see Comment]. Circulation. 2008;117(8): 1018-1027.

43. Vogelzang M, van der Horst ICC, Nijsten MWN. Hyperglycaemic index as a tool to assess glucose control: a retrospective study. Crit Care. 2004; 8(3):R122-R127.

44. Schnipper JL, Magee M, Larsen K, Inzucchi SE, Maynard G. SHM glycemic control task force summary: practical recommendations for assessing the impact of glycemic control efforts. J Hosp Med. 2008;3(S5):66-75.

45. Cook CB, Zimmerman RS, Gauthier SM, et al. Understanding and improving management of inpatient diabetes mellitus: The Mayo Clinic Arizona Experience. J Diabetes Sci Technol. 2008;2:925-931.

46. Kanji S, Buffie J, Hutton B, et al. Reliability of point-of-care testing for glucose measurement in critically ill adults. Crit Care Med. 2005;33(12): 2778-2785.

47. Desachy A, Vuagnat AC, Ghazali AD, et al. Accuracy of bedside glucometry in critically ill patients: influence of clinical characteristics and perfusion index. Mayo Clin Proc. 2008;83:400-405. 